\title{
Vibration Analysis of Industrial Air Blower using Finite Element Analysis
}

\author{
Rohit Gawali $^{1}$, Shrikant Awatade ${ }^{2}$, Anand Nilewar ${ }^{3}$ \\ ${ }^{1} P G$ Scholar, Department of Mechanical Engineering, \\ Priyadarshini College of Engineering, Nagpur, India, 440019 \\ ${ }^{2}$ Assistant Professor, Department of Mechanical Engineering, \\ Priyadarshini College of Engineering, Nagpur, India, 440019
}

DOI: 10.46335/IJIES.2020.5.10.7

\begin{abstract}
This paper discusses the end-user complaint area of Industries. In this report, both technically and using a finite element analysis approach, the influence of design parameters on the fan noise frequency of the centrifugal blower impeller are studied. Studies of finite element analysis was conducted to test the theoretical conclusions and also to explore the influence of various configuration alternatives on the fan's noise frequency. The study of the Finite elements implies that the empirical and theoretical results are in strong agreement. The experimental research of numerous fan configurations provides details on the possibilities for noise reduction. Any vibration will still be produced by the operation of some mechanical device. Our goal is to mitigate the influence of these vibrations, since vibration is inevitable although undesirable. From nuisance interruption to a disastrous collapse, the outcome of excess vibration may differ. Any vibration must be produced by all fans. They constantly rotate and, because nothing is ideal, it is important to produce cyclic powers. It is only when a certain amplitude of vibration crosses that we call it evil. Vibration may be merely an indication of any process problem, or it may be a source of other issues. Finally, vibration may propagate into neighboring areas and interact with processes of precision, or cause irritation for individuals. The goal of this thesis is therefore to present centrifugal blower vibration analysis for materials like steel, aluminum and composite (glass / epoxy).
\end{abstract}

Keywords- Centrifugal Blower, Impeller, Static, Modal and Harmonic Response, CATIA V5 R19, ANSYS 14.5.7.

\section{I- INTRODUCTION}

$\mathrm{F}$ ans and blowers provide air needed for ventilation and industrial processes [1]. Fans produce a pressure in a fan system to transfer air (or gases) against a resistance created by ducts, dampers or other parts [2], [3], [4]. The ventilator rotor collects and transmits energy from a spinning shaft to the air [5], [6], [7]. One of the essential components used daily in Boiler service is blowers. Highly effective fans will make Boiler more powerful. Using Forced Draught (FD) fans, they are used to supply air for fuel combustion in boiler furnace, mounted on the front side of the furnace supplying air either at normal temperature or at elevated temperature, whether air is supplied using air-pre heater [8], [9], [10]. The fans must have a high enough pressure strength to withstand the complete resistance of inlet silencers, air preheating cables, air ducts, air heaters, wind boxes, flame registers, and all other resistance between the fan and furnace air intake [11], [12], [13]. Using Induced Draught (ID) fans, the flue gases produced following fuel combustion can be drawn out. They keep the furnace pressure well below atmospheric pressure. Main Air (PA) fans are used for the atomization of pulverized fuel to provide combustion air. Secondary Air (SA) fans are used to transfer pulverized fuel by way of duct conveying system. FD, 
SA, and PA are usually direct drive fans while ID fans are belt driven fans.

\section{II- COMPUTER AIDED MODELING AND SPECIFICATION OF AIR BLOWER}

There are three loading styles which actually work on the centrifugal fan impeller [14], [15], [16]. The first is the centrifugal force induced by rotation of the impeller which results in centrifugal acceleration of the body of the impeller. The second is that arising from increasing temperature caused by thermal expansion. The last one is the aerodynamic force between the blade and the air resulting from the change of friction [17].

The impeller considered for case study has OD $660 \mathrm{~mm}$, ID $200 \mathrm{~mm}$, blade width at the front edge is $45 \mathrm{~mm}$, blade width at trailing edge is thirty $\mathrm{mm}$, back plate thickness is six mm, blade thickness is five $\mathrm{mm}$ and shroud is four mm. Twelve is the number of knives. The impeller's rotational speed is $2900 \mathrm{rpm}$.

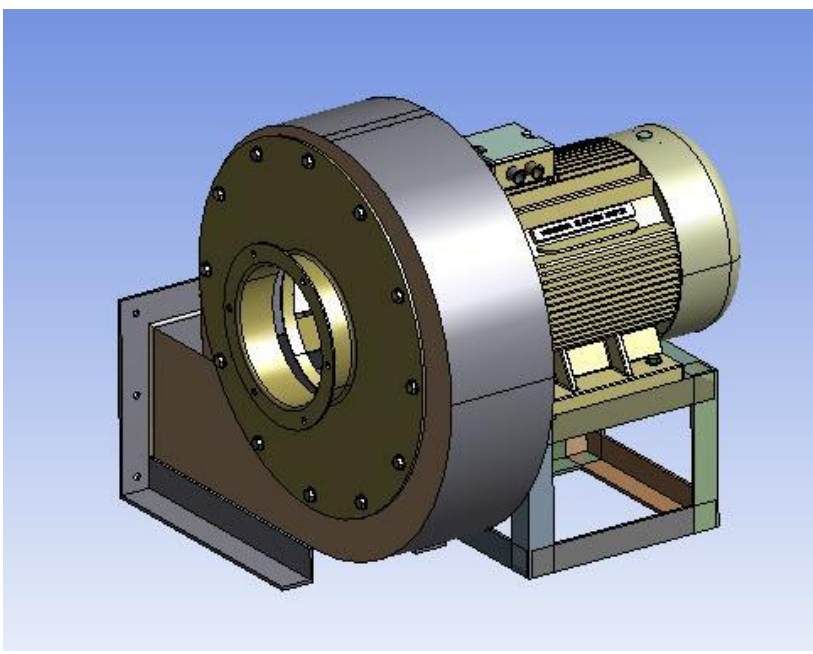

Fig 1-CAD Model of Air Blower

Based on the design criteria, the CAD model is prepared with the help of CATIA V5 R19.

Meshing and centrifugal blower research was conducted using the general purpose FEM programme ANSYS 14.5.7. The materials chosen here are usually used for fabrication purpose of blower viz., steel, aluminium and glass / epoxy.

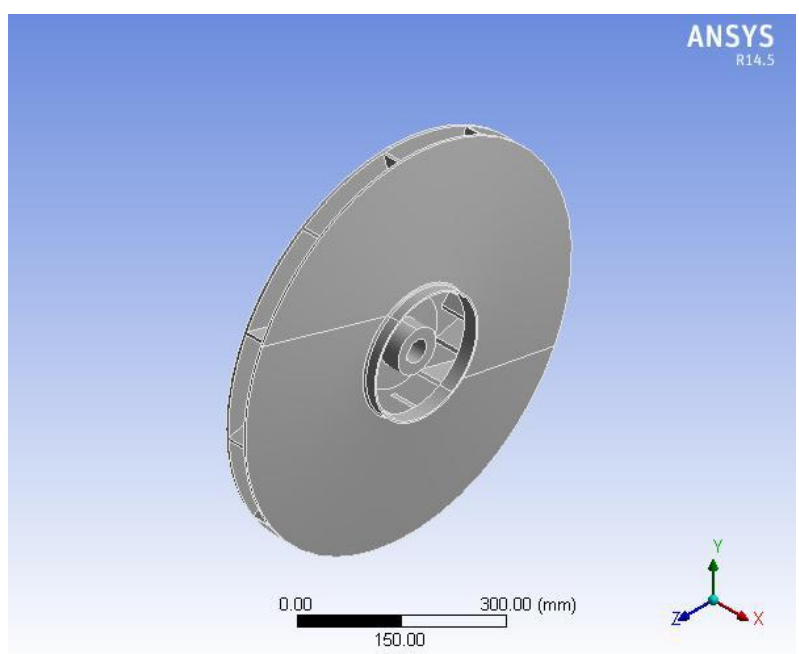

Fig 2- CAD Model of blower impeller

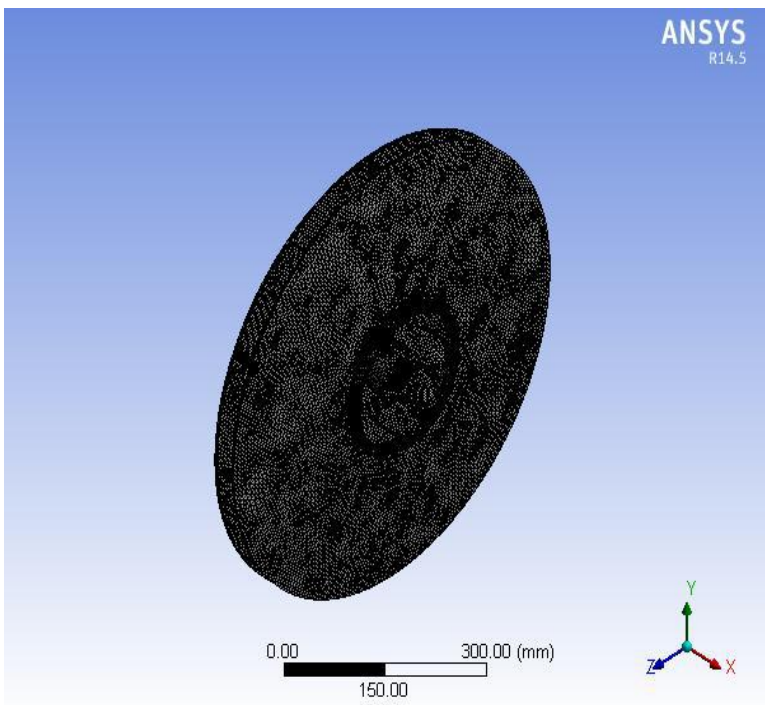

Fig 3-Meshing of blower impeller

\section{III- RESULTS AND DISCUSSIONS}

Table 1 shows the material properties of steel and aluminum materials

Table 1 Material Properties of steel and aluminium materials

\begin{tabular}{|c|c|c|c|}
\hline S N. & Properties & Steel & Aluminium \\
\hline 1 & Density (kg/m3) & 7850 & 2770 \\
\hline 2 & Yield Strength (Mpa) & 250 & 280 \\
\hline 3 & $\begin{array}{c}\text { Ultimate tensile } \\
\text { Strength (Mpa) }\end{array}$ & 460 & 310 \\
\hline 4 & Poisson's ratio & 0.3 & 0.33 \\
\hline 5 & $\begin{array}{c}\text { Young's } \\
\text { modulus(Gpa) }\end{array}$ & 200 & 71 \\
\hline 6 & Bulk modulus (Gpa) & 167 & 69.61 \\
\hline 7 & Shear Modulus (Gpa) & 76.923 & 26.7 \\
\hline
\end{tabular}


International Journal of Innovations in Engineering and Science, Vol 5, No.9, 2020

\section{www.ijies.net}

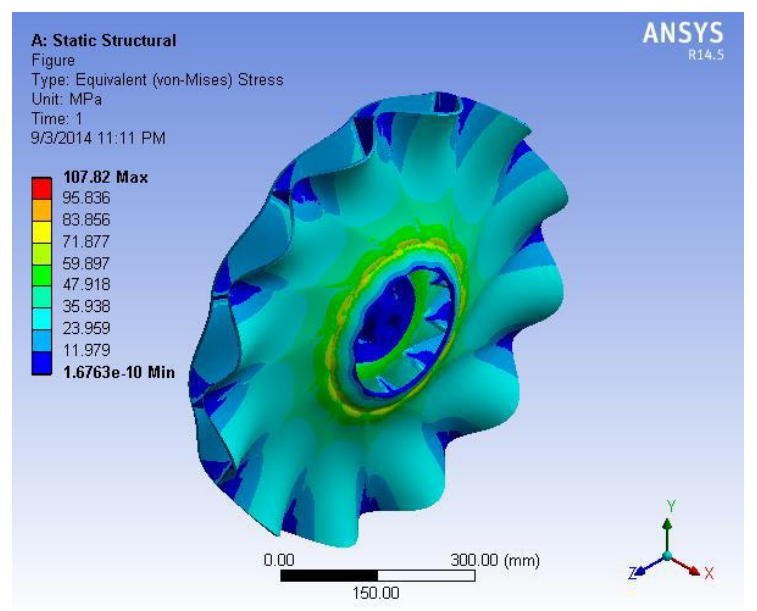

Fig 4- Equivalent (von-mises) stress of blower impeller (steel)

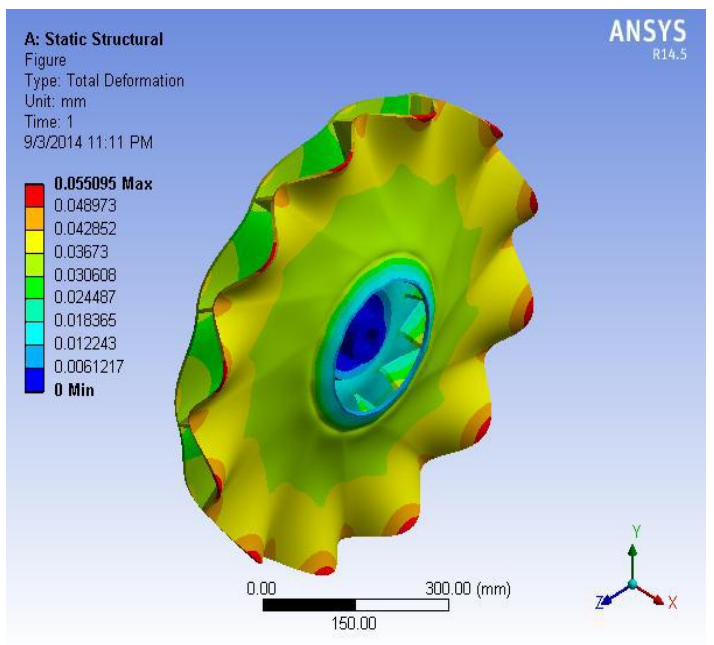

Fig 5-Total deformation of blower impeller (steel)

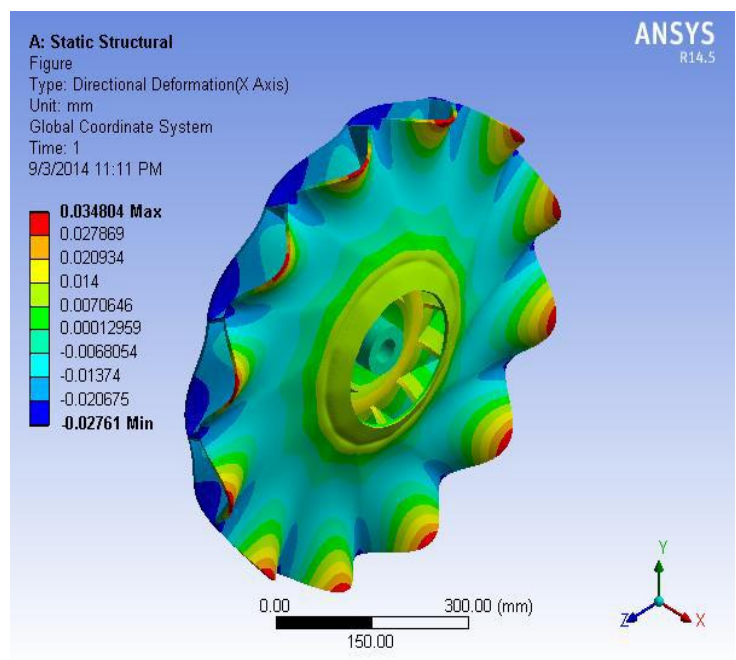

Fig 6- Directional deformation (x-axis) of blower impeller (steel)

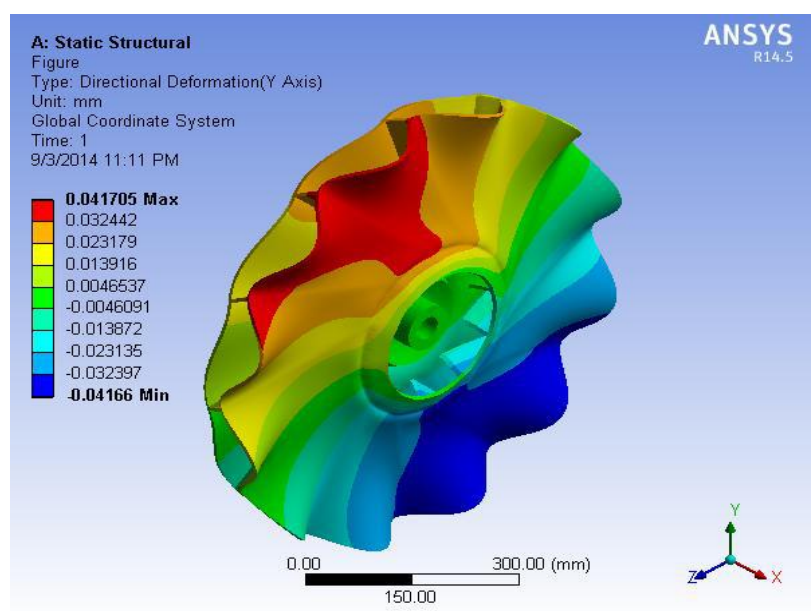

Fig 7-Directional deformation (y-axis) of blower impeller (steel)

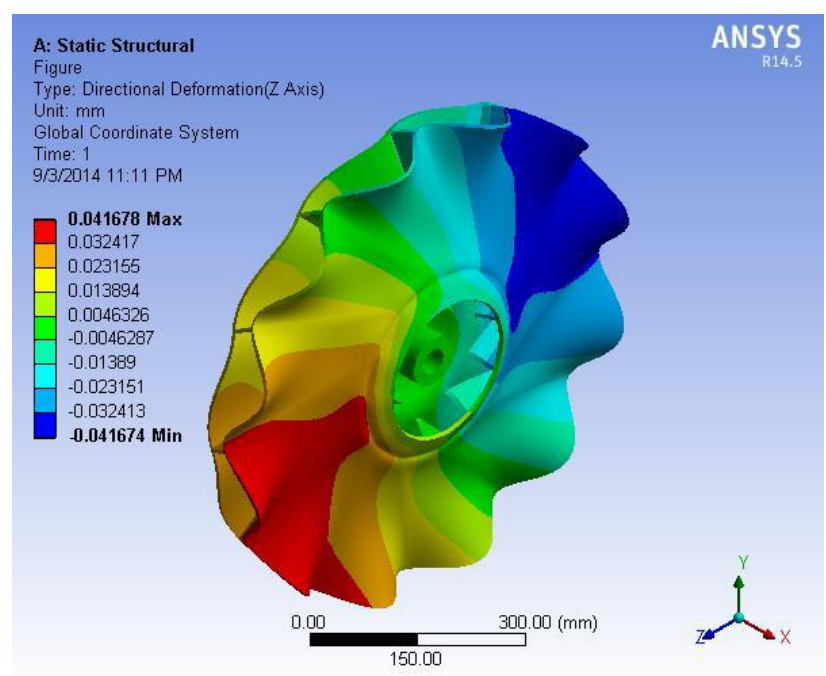

Fig 8-Directional deformation (z-axis) of blower impeller (steel)

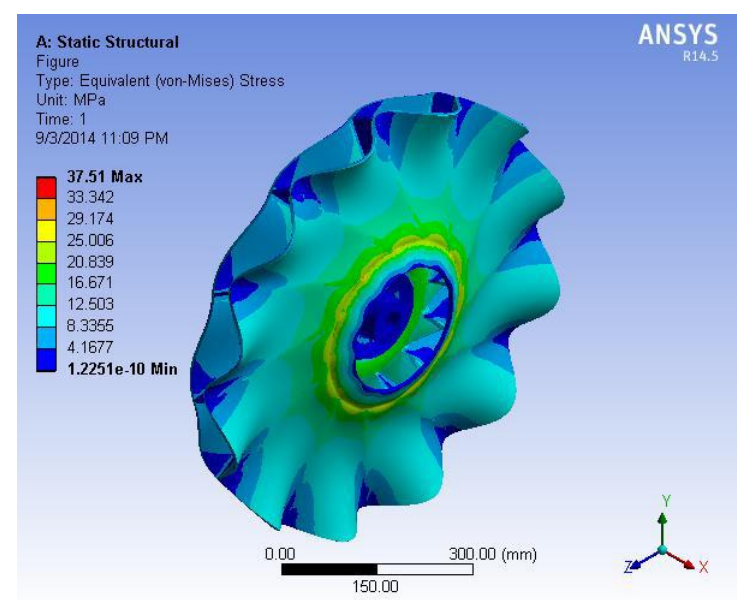

Fig 9- Equivalent (von-mises) stress of blower impeller (aluminium) 


\section{$w w w . i j i e s . n e t$}

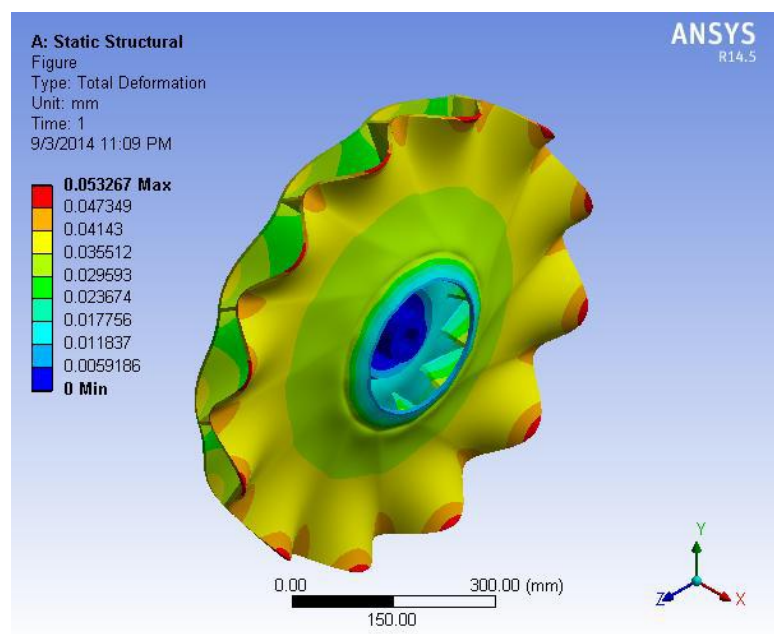

Fig 10-Total deformation of blower impeller (aluminium)

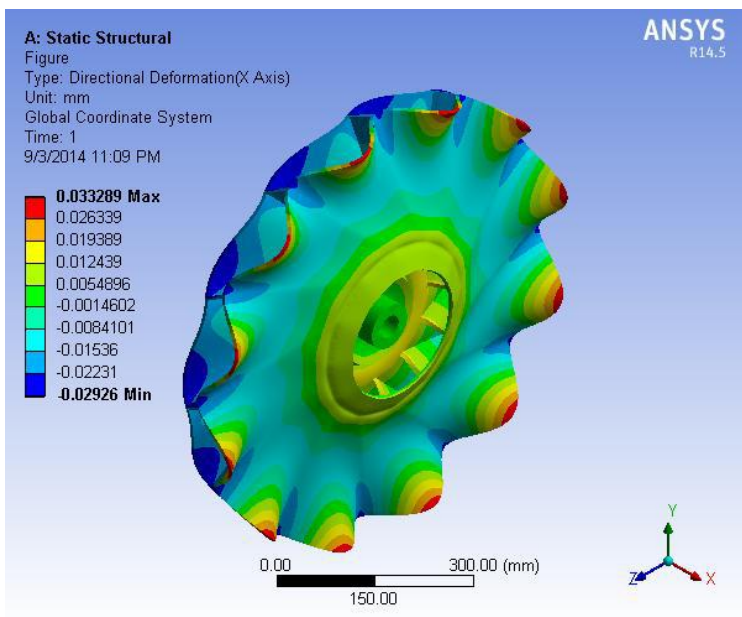

Fig 11-Directional deformation (x-axis) of blower impeller (aluminium)

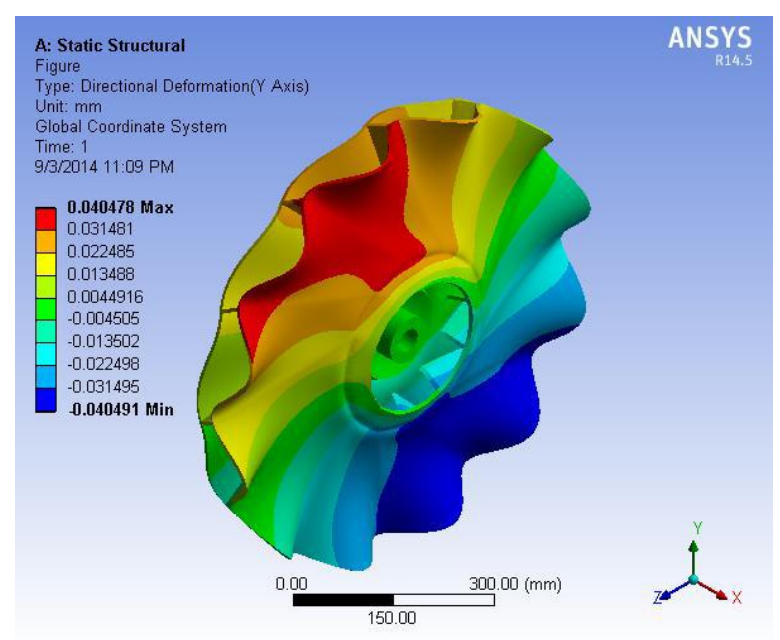

Fig 12-Directional deformation (y-axis) of blower impeller (aluminium)

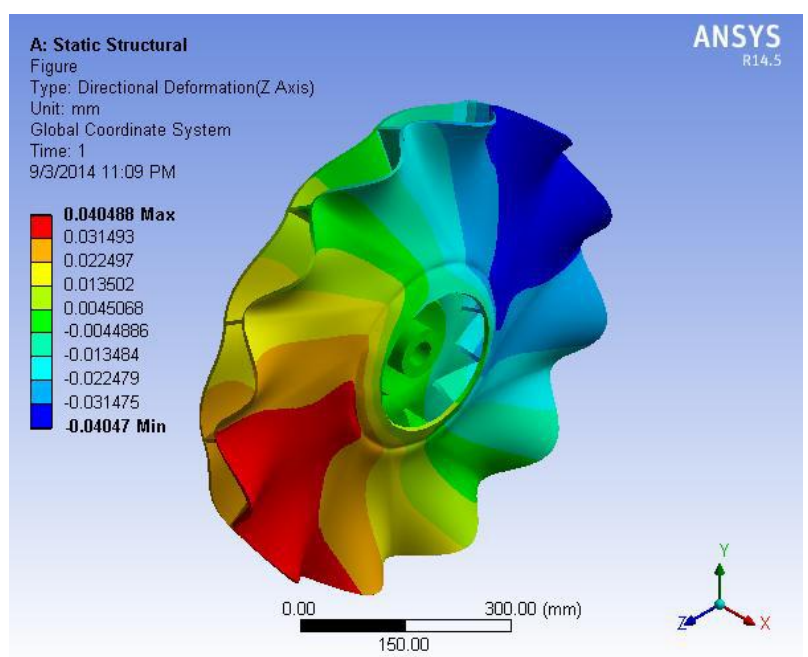

Fig 13-Directional deformation (z-axis) of blower impeller (aluminium)

Table 2 Material Properties of Composite (Glass/Epoxy)

\begin{tabular}{|c|c|c|}
\hline S. N. & Properties & $\begin{array}{c}\text { Composite } \\
\text { (Glass/Epoxy) }\end{array}$ \\
\hline 1 & Density (kg/m3) & 1750 \\
\hline 2 & Poisson's ratio (xy) & 0.13 \\
\hline 3 & Poisson's ratio (yz) & 0.39 \\
\hline 4 & Poisson's ratio (zx) & 0.39 \\
\hline 5 & Young's modulus (x) (Gpa) & 14 \\
\hline 6 & Young's modulus (y) (Gpa) & 14 \\
\hline 7 & Young's modulus (z) (Gpa) & 8.8 \\
\hline 8 & Shear modulus (xy) (Gpa) & 4.7 \\
\hline 9 & Shear modulus (yz) (Gpa) & 4.2 \\
\hline 10 & Shear modulus (zx) (Gpa) & 4.2 \\
\hline 11 & Constant damping & 0.02 \\
& coefficient & \\
\hline
\end{tabular}

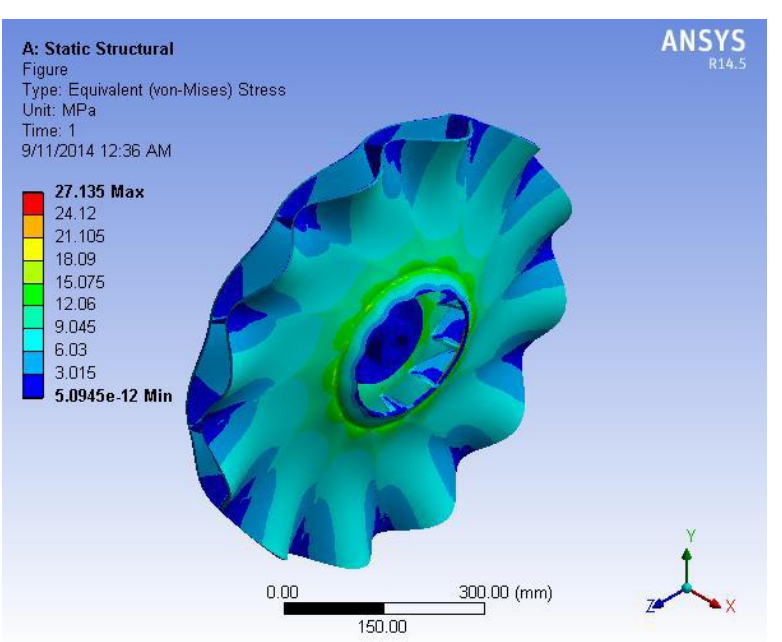

Fig 14-Equivalent (von-mises) stress of blower impeller (glass/epoxy) 


\section{$w w w . i j i e s . n e t$}

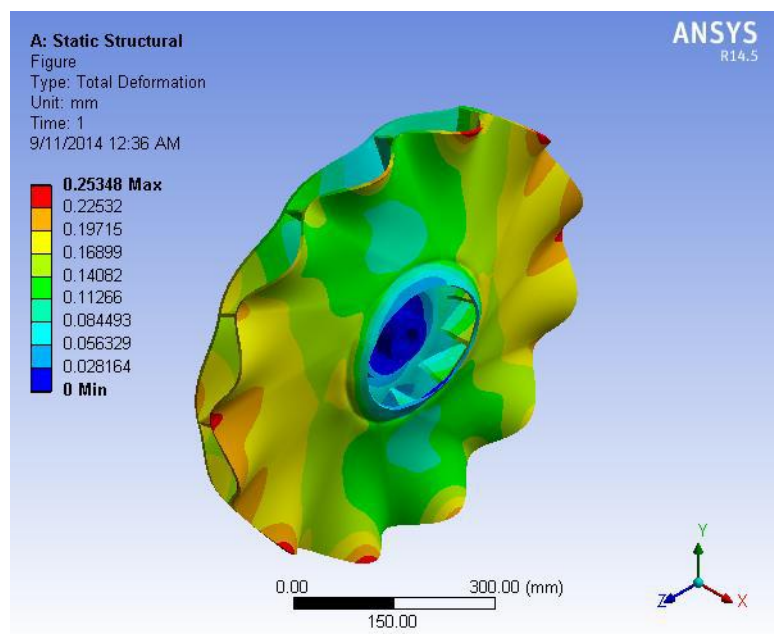

Fig 15- Total deformation of blower impeller (glass/epoxy)

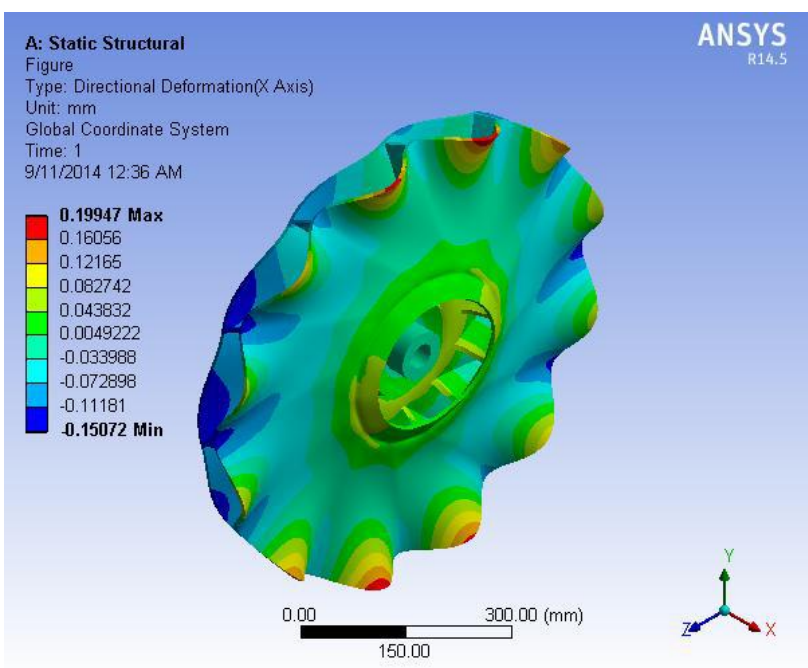

Fig 16- Directional deformation (x-axis) of blower impeller (glass/epoxy)

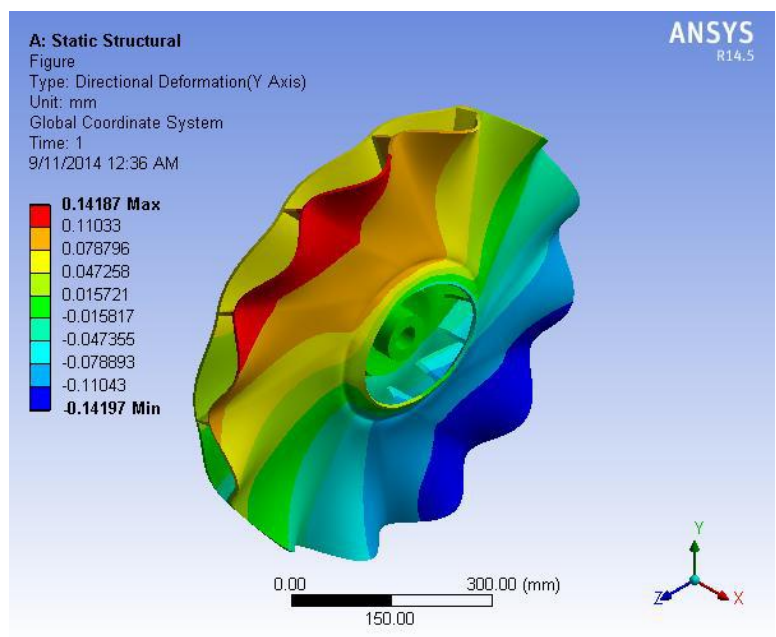

Fig 17- Directional deformation (y-axis) of blower impeller (glass/epoxy)

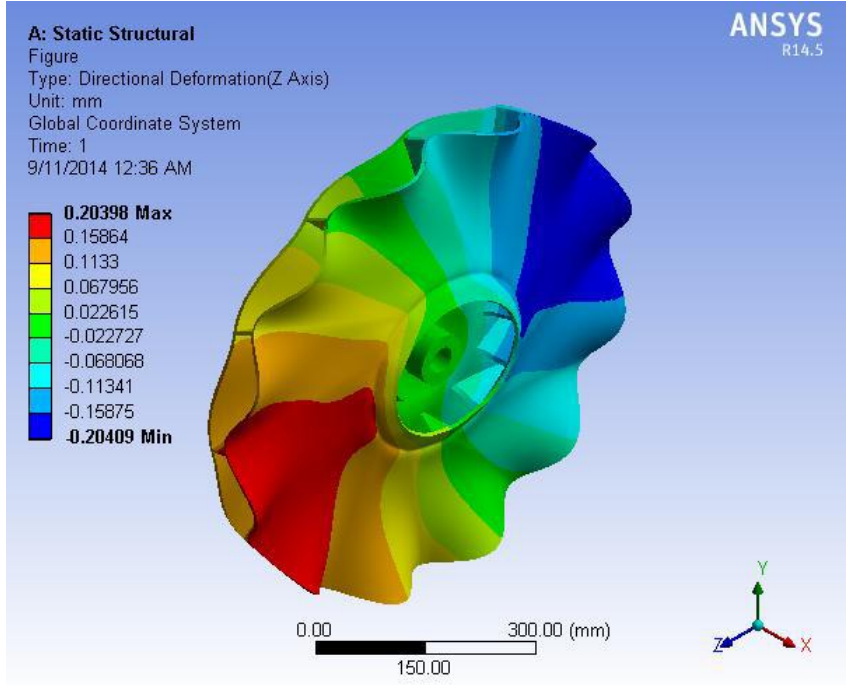

Fig 18-Directional deformation (z-axis) of blower impeller (glass/epoxy)

Table 3 Comparative Analysis of the materials

\begin{tabular}{|c|c|c|c|}
\hline $\begin{array}{c}\text { Parameter / } \\
\text { Material }\end{array}$ & Steel & Aluminum & $\begin{array}{l}\text { Glass/ } \\
\text { Epoxy }\end{array}$ \\
\hline Mass (kg) & 31.17 & 12.06 & 07.62 \\
\hline Nodes & 294869 & 294675 & 283951 \\
\hline Elements & 147959 & 147969 & 142684 \\
\hline $\begin{array}{c}\text { Equivalent } \\
\text { Stress (MPa) }\end{array}$ & 107.82 & 37.51 & 27.135 \\
\hline $\begin{array}{c}\text { Total } \\
\text { Deformation } \\
(\mathrm{mm})\end{array}$ & 0.0551 & 0.0532 & 0.2535 \\
\hline $\begin{array}{c}\mathrm{x} \text {-axis } \\
\text { deformation } \\
(\mathrm{mm})\end{array}$ & 0.03481 & 0.03328 & 0.19947 \\
\hline $\begin{array}{c}y \text {-axis } \\
\text { deformation } \\
(\mathrm{mm})\end{array}$ & 0.04171 & 0.04047 & 0.14187 \\
\hline $\begin{array}{c}\text { z-axis } \\
\text { deformation } \\
(\mathrm{mm})\end{array}$ & 0.04167 & 0.04048 & 0.20398 \\
\hline Mode number & \multicolumn{3}{|c|}{ Prestressed natural frequency } \\
\hline 1 & 122.3 & 123.61 & 75.157 \\
\hline 2 & 122.36 & 123.71 & 76.525 \\
\hline 3 & 314.95 & 318.36 & 161.71 \\
\hline 4 & 403.88 & 401.37 & 201.31 \\
\hline 5 & 414.66 & 415.01 & 218.86 \\
\hline 6 & 414.73 & 415.09 & 220.93 \\
\hline 7 & 696.07 & 697.06 & 364.72 \\
\hline $\begin{array}{c}\mathrm{x} \text {-axis } \\
\text { amplitude } \mathrm{v} / \mathrm{s} \\
\text { frequency } \\
(\mathrm{mm})\end{array}$ & 0.01133 & 0.03472 & 0.14873 \\
\hline $\begin{array}{c}\text { y-axis } \\
\text { amplitude v/s } \\
\text { frequency } \\
(\mathrm{mm})\end{array}$ & 0.00498 & 0.013905 & 0.03684 \\
\hline $\begin{array}{c}\mathrm{z} \text {-axis } \\
\text { amplitude } \mathrm{v} / \mathrm{s} \\
\text { frequency } \\
(\mathrm{mm})\end{array}$ & 0.00505 & 0.01405 & 0.03832 \\
\hline
\end{tabular}




\section{IV- CONCLUSION}

The impeller mass, retaining the same thickness of the components of the impeller, decreases due to density in the series of steel, aluminium and glass / epoxy. Less glass / epoxy equivalent stress, less aluminium and strong steel equivalent stress. Aluminum 's total and directional deformation is slightly less than that of steel. Compared with steel and aluminium, overall and lateral deformation for glass / epoxy is higher. For steel and aluminium, the natural pre-stressed frequency is almost identical. In contrast to steel and aluminium, the prestressed natural incidence for glass / epoxy is very poor. For glass / epoxy, less for aluminium and less for steel, axial $(\mathrm{x}, \mathrm{y}$, and $\mathrm{z})$ deformation amplitude versus frequency is high.

\section{REFERENCES}

[1] Waghmare SN, Sakhale CN, Tembhurkar CK, Shelare SD. Assessment of Average Resistive Torque for Human-Powered Stirrup Making Process. Computing in Engineering and Technology [Internet]. Springer Singapore; 2019 Oct 17;845-53. Available from: http://dx.doi.org/10.1007/978-981-32-9515-5_79

[2] Waghmare SN, Shelare SD, Tembhurkar CK, Jawalekar SB. Development of a Model for the Number of Bends During Stirrup Making Process. Advances in Metrology and Measurement of Engineering Surfaces [Internet]. Springer Singapore; 2020 Jun 16;69-78. Available from: http://dx.doi.org/10.1007/978-981-155151-2_7

[3] Shelare SD, Kumar R, Khope PB. Formulation of a Mathematical Model for Quantity of Deshelled Nut in Charoli Nut Deshelling Machine. Advances in Metrology and Measurement of Engineering Surfaces [Internet]. Springer Singapore; 2020 Jun 16;89-97. Available from: http://dx.doi.org/10.1007/978-981-155151-2_9

[4] Waghmare S., Shelare S., Sirsat P., Pathare N, Awatade S. (2020) Development of An Innovative Multi-Operational Furnace. International Journal of Scientific \& Technology Research Volume 9, Issue 04, April 2020. Pp 885-889.

[5] Jawalekar, S. B., and S. D. Shelare. 2020. Development and performance analysis of low cost combined harvester for rabicrops. Agricultural Engineering International:CIGR Journal, 22 (1):197-201.

[6] S. D. Shelare, P.S. Thakare and Dr. C. C. Handa, "Computer Aided Modelling and Position Analysis of Crank and Slotted Lever Mechanism", International Journal of Mechanical Engineering and Production engineering Research and Development, Volume 2, No 2, June 2012, PP 47-52.

[7] Mehta, Girish and Deogirkar, Sagar and Borkar, Prerna and Shelare, Sagar and Sontakke, Sonam, Estimation of Vibration Response of a Bridge Column (February 24, 2019). Proceedings of International Conference on Sustainable Computing in Science, Technology and Management (SUSCOM), Amity University Rajasthan, Jaipur - India, February 26-28, 2019, Available at SSRN: https://ssrn.com/abstract $=3356326$ or http://dx.doi.org/10.2139/ssrn.3356326

[8] Mali, P., C.Sakhale, and S. Shelare.2015. A literature review on design and development of maize thresher. International
Journal of New Technologies in Science and Engineering, 3(9):9-14

[9] Kumbhare H., Shelare S.. (2020) Innovative Advancement in Drone Technology for Water Sample Collections -A Review. International Journal of Scientific \& Technology Research Volume 9, Issue 03, March 2020. Pp 7266-7269.

[10] Mowade S, Waghmare S, Shelare S, Tembhurkar C. Mathematical Model for Convective Heat Transfer Coefficient During Solar Drying Process of Green Herbs. Computing in Engineering and Technology [Internet]. Springer Singapore; 2019 Oct 17;867-77. Available from: http://dx.doi.org/10.1007/978-981-32-9515-5_81

[11] Mathew JJ, Sakhale CN, Shelare SD. Latest Trends in Sheet Metal Components and Its Processes-A Literature Review. Algorithms for Intelligent Systems [Internet]. Springer Singapore; 2020;565-74. Available from: http://dx.doi.org/10.1007/978-981-15-0222-4_54

[12] Sakhale C.N., Bapat P.M. and Singh M.P., -Design Of Experimentation And Application of Methodology of Engineering Experimentation To Investigation Of Processing Torque, Energy And Time Required In Bamboo Processing Operationsl, International Journal of Bamboo and Rattan, April 2011 Vol. 9. 1 \&2, Jbr 284, Pp:13-27.

[13] Design and Analysis of Power Screw for Manhole Cover Lifter. 2 [Internet]. Blue Eyes Intelligence Engineering and Sciences Engineering and Sciences Publication - BEIESP; 2019 Jul 30;8(2):2782-6. Available from: http://dx.doi.org/10.35940/ijrte.b2628.078219

[14] Sakhale C.N., Bapat P.M., Singh M.P., ModakJ.P., "Design of a Comprehensive Bamboo processing Machine”, IFTToM:PICA2006, 11th-14th July,2006, Vol.1, Pp.51-54.

[15] Sahu P., Shelare S., Sakhale C. (2020) Smart Cities Waste Management And Disposal System By Smart System: A Review. International Journal of Scientific \& Technology Research Volume 9, Issue 03, March 2020. Pp 4467-4470.

[16] S. N. Waghmare et al., SNW et al. A Case Study on Improvement of Plant Layout for Effective Production. International Journal of Mechanical and Production Engineering Research and Development [Internet]. Transstellar Journal Publications and Research Consultancy Private Limited; 2017;7(5):155-60. Available from: http://dx.doi.org/10.24247/ijmperdoct201716

[17] Shelare S D, Handa C. Tsynthesis in Simulation and sensitivity analysis of quick return mechanism. LAP LAMBERT Academic Publishing: December (2012). 